\section{The dissolution of semantics}

SIR - In a previous report ${ }^{1}$, we described a patient with an impairment of comprehension apparently restricted to certain semantic categories in the auditory-verbal domain. This category and modality specific disorder was associated with a local degenerative condition ${ }^{2}$. We now describe the further degeneration of semantic knowledge we have observed.

When first assessed, the patient (T.O.B.) had a consistent impairment of his ability to comprehend the spoken names of living things, but remarkably, he had no difficulty in comprehending pictures of the same items. His comprehension of objects was good with both visual and auditory presentation. Because his impairment was specific both to the modality of presentation and to a semantic category, we challenged the orthodox view that knowledge is represented in a "general purpose" semantic system. Our conclusion, neatly summarized by Marshall" ${ }^{3}$, was that "semantic information is multiply represented in the normal brain and this duplication is linked to the input modalities whereby we gain knowledge of the world".

T.O.B. has since been seen regularly for clinical counselling and for the serial assessment of his comprehension difficulties. His condition remained remarkably stable for six months (December 1987 to May 1988), but by May 1989 there had been a clear deterioration in his verbal comprehension. He remained able to express himself volubly, but became increasingly circumlocutory and reliant on stereotyped phrases.

In the original test session, T.O.B. was asked to define the spoken names of 48 objects and 48 living things, as well as to 'define' pictures of the same stimulus items. Although he was unable to name the picture stimuli, he was often able to provide adequate 'picture definitions' conveying the core concept. Thus, when asked to define the spoken word 'dolphin', T.O.B. replied "a fish or a bird", whereas when shown a picture of a dolphin he responded "lives in water... they are trained to jump up and come out ... In America during the war years they started to get this particular animal to go through to look into ships". He was subsequently re-tested on this same stimulus pool 6 and 18 months later (see figure). The results show a marked decline in T.O.B.'s comprehension, but even on his most recent assessment he still shows effects of modality of presentation and semantic category.

T.O.B.'s knowledge of the spoken names of living things has shown a significant decline (binomial test $N=14, x=0, P$ $<0.001$ ); his knowledge of pictures of living things (which was previously rela- tively intact), is now significantly worse (binomial test $N=15, x=0, P<0.001$ ). In the case of objects, there has been a deterioration in his knowledge of many spoken names that he knew previously (binomial test $N=16, x=0, P<0.001)$. For example, in 1987 he was able to define the word

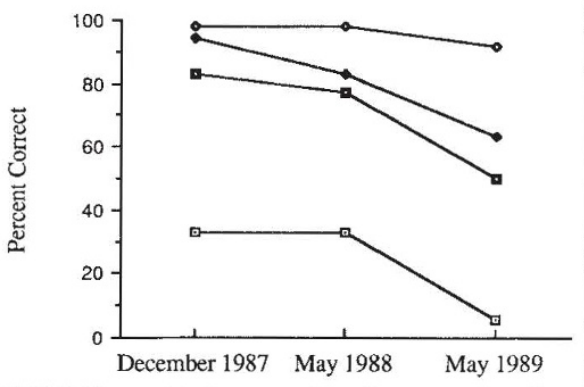

T.O.B. Percentage correct on three successive assessments. Open squares, living things (auditory); filled diamonds, living things (visual); filled squares, objects (auditory); open diamonds, objects (visual).

'canoe' as a "small version of a boat, long and narrow, one or 2 people" whereas, by 1989 , all he could say was "a common word to me". But there has been no significant deterioration for one category of knowledge, namely visual objects. For example, T.O.B. was able to describe a picture of a thermometer as "for temperature, automatically records the actual temperatures that there are". Indeed, were one to have examined T.O.B. for the first time at this stage in his illness he might well have been characterized as a
SIR - von Schantz et al. recently reported ${ }^{1}$ that long-spurred male pheasants (Phasianus colchicus) survive better than short-spurred males, are preferred as mates by female pheasants, and that those females mating with long-spurred males produce more offspring. These results are of great significance to current controversies in sexual selection theory $y^{2,3}$. But the data of von Schantz et al. in fact challenge their interpretation that the genetic superiority of long-spurred males is directly responsible for the increased reproductive success of females mating with them.

von Schantz et al. quantified female reproductive success by the number of chicks hatched. In most birds, the most important cause of variation in hatching success is predation ${ }^{4}$. Because differences in the male genetic contribution to eggs should not affect their vulnerability to predators, the effects of predation should be removed from the analysis before assessing whether paternal quality directly influences hatching success. Because predation is usually absolute (that is, all eggs in a clutch are destroyed), the effect case with an 'island' of preserved knowledge specific to inanimate objects in the visual modality. The pattern of impairment on the most recent serial assessment is the obverse of that documented on the first.

Because the sclective preservation of knowledge may be as informative as its selective loss, we would argue that the present evidence adds further weight to the contention that there are modality and category specific cerebral meaning systems. This conclusion is strengthened by the documentation of different rates of degeneration in T.O.B.'s verbal and visual knowledge. Were a single 'semantic' store implicated, it would be hard to explain why verbal knowledge should deteriorate more rapidly than visual knowledge, and still less why a categoryspecific profile of impairment should be maintained.

ROSALEEN MCCARTHY* Department of Experimental Psychology, University of Cambridge,

Downing Street,

Cambridge CB2 3EB,

UK

ELIZABETH K. WARRINGTON

Department of Psychology*,

The National Hospitals,

Queen Square,

London WC1N 3BG,

UK

1. McCarthy, R.A. \& Warrington, E.K. Nature $334,428 \sim 430$ (1988)

2. Tyrell, P.J., Warrington, E.K., Frackowiak, R.S.J. \& Rossor, M.N. Brain (in the press)

3. Marshall, J.C. Nature 334, 378 (1988).

\title{
Genetics of long-spurred pheasants
}

of predation can be largely eliminated by excluding from the analysis all clutches in which no eggs hatched. (In nests suffering no predation, hatching success usually exceeds $80 \%$, see ref. 5 .) If clutches hatching no young are eliminated from Fig. $1 b$ of ref. 1, the significant correlation between male spur length and female reproductive success disappears $\left(r^{2}=\right.$ $0.02, P=0.45, N=30$ ).

What this implies is that the increased reproductive success of females mating with long-spurred males arises, not because they lay eggs of intrinsically high viability, but because their nests suffer less predation. As males do not contribute to the care of nests ${ }^{1}$, reduced predation cannot be attributed to better parenthood by long-spurred males. Perhaps, as Kirkpatrick $^{2}$ suggested in his News and Views article accompanying ref. 1, female pheasants are behaving like Burley's ${ }^{6}$ female zebra finches, providing better care for eggs sired by superior males. It remains to be demonstrated that females mating with superior males have higher reproductive success independent of their 